\title{
Diversity and Foraging Behaviour of Insect Pollinators on Murraya koenigii (L. ) (Rutaceae)
}

\author{
M. M. Dhore
}

Shri Shivaji Arts, Commerce and Science College, Akot, Maharashtra, India

\begin{abstract}
The present studies on diversity and foraging behaviour of insect pollinators on Murraya koenigii (L. )was carried out during March - April 2019 at Akot town situated in Akola district of Maharashtra. Ten insect species visited Murraya koenigii flowers viz. Five hymenopterans and five lepidopterons. This study revealed that hymenopterans were found to be the most dominant (97. 5\%) flower visitors, followed by lepidopteron insects (2. 5\%). Among these Apis florea, Apis cerana indica, and Apis dorsata were found to be the most frequent pollinators. The result on foraging behaviour of bees Apis florea started visiting Murrya koenigii flowers in early morning at $06.00 \mathrm{hrs}$, Apis cerana indica at $6.30 \mathrm{hrs}$ and ceased their activity later in the evening. Apis mellifera and Apis dorsata, they started visiting the flowers from 7. 00hrs. Maximum foraging was by Apis florea (12 flowers /minute)followed by Apis cerana indica (10 flowers/minute )and Apis dorsata (910 flowers /minute). Time spent per flower was the maximum with lepidopteron ( $25 \mathrm{sec}$. /flower) followed by Moth (15 sec. /flower)
\end{abstract}

Keywords : Murraya Koenigii, Insect, Foraging Behaviour, Apis Florea

\section{INTRODUCTION}

Pollination plays an important role in the reproduction and fruit set of flowering plants ( Corbet et. al 1991, Buchmann and Nabhan 1996). Many agricultural crops and natural plant population are dependent on pollination and offer on the services provided by wild, unmanaged, pollinator communities ( Free, 1993, Kluser and Peduzzi, 2007). Insect pollinators especially honeybees play an important role in pollination of many wild and cultivated plants. These helps in increasing the quality and quantity of agricultural produce (Sihag, 1986)

Murraya koenigii (L. )belongs to the family Rutaceae and is a native of India, Srilanka and other south Asia contries. It is more or less deciduous shrub or small tree. It is aromatic in nature. Flowers are produced in terminal cymes, each bearing 50-65 flowers . Flowers, ebracteate, white, sweet scented, fragrant, bisexual, complete, actinomorphic and hypogynous.

Murraya koenigii is a potential medicinal plant highly valued for its characteristic aroma and bioactive compounds. Murraya koenigii has diverse role in traditional medicine and is known for its stomachic properties. Leaves are often used in curries for flavouring and seasoning due to their aromatic nature. The bioactive compound possess antioxidant, antimicrobial, anthelmentic, analgesic, antiinflammatory, antidiarrhal properties (Gahlawat et al 2014).

By keeping this view, the present study was carried out to record the different insect pollinators and foraging behaviour of honeybees visiting Murraya koenigii flowers. 


\section{MATERIAL AND METHODS}

The study was carried out in Akot situated in Akola district of Maharashtra during March-April 2019. Akot town lies between latitude 21. $06 \mathrm{~N}$ and longitude 77. $06 \mathrm{E}$ in the northern most of the Akola district of Maharashtra.

Observations on the insect pollinators visiting the flowers of Murraya koenigii was recorded during the peak flowering period. The number of flowers visited by visitors was recorded at 2 hrs intervals between 06 . 00 hrs - 18. 00 hrs. The photographs of selected visitors were also taken. The foraging rate of different types of insect visitors was recorded in terms of the number of flowers visited per minute. The foraging speed of bees was recorded in terms of the time spent by each species on a flower. The observations on foraging behaviour of insect visitors were undertaken consecutively for 15 days.

\section{RESULTS AND DISCUSSION}

Flowering period of Murraya koenigii was started from first week of March and lasted till end of April. The peak period of flowering in Murraya koenigii was observed to be the last week of March to second week of April. Flowers were borne in terminal cymes , white in colour and sweet scented. During the observation 10 insect species belonging to seven families of two orders, Hymenoptera and Lepidoptera (Table 1) were recorded during the peak flowering period of Murraya koenigii plants. Among all , major floral visitors were the hymenopterans comprising of six species viz. Apis florea, Apis cerana indica, Apis mellifera Apis dorsata, Moth and five species from Lepidoptera viz. Barbo cinnara, Catopsilla pyranthe, Pachliopta aristolochiae, Hypolimnas bolina and unidentified butterfly. The bees Apis cerana indica, Apis florea and Apis dorsata were found to be major and frequently observed visitors. Butterflies Barbo cinnara, Catopsilla pyranthe, Pachliopta aristolochiae, Hypolimnas bolina, unidentified butterfly and Moth were the occasional visitors (Table1). Among the different insect pollinators, Apis florea was the predominant species found to visit the inflorescence during the entire flowering period. Results showed that Apis florea commenced its foraging activity very early in the morning 6. 00hrs and peaked during 09 . 00-15. 00 hrs declined at $17.00 \mathrm{hrs}$ and was very low at $18.00 \mathrm{hrs}$. Apis cerana indica began foraging after half an hour of Apis florea at $6.30 \mathrm{hrs}$, peaked during 1100-1300hrs. The bees Apis florea and Apis cerana indica after landing on the inflorescence walked on the same and collected pollen and nectar from flowers. Apis dorsata started foraging at 6. $30 \mathrm{hrs,} \mathrm{peaked}$ during 10. $00-13.00 \mathrm{hrs}$ declined in the afternoon and was not recorded at $18.00 \mathrm{hrs}$. Of all the insect visitors , Apis florea, Apis cerana indica and Apis dorsata were the most abundant visitors. Apis mellifera was found to be the least abundant among order hymenoptera. Foraging speed of different honeybees in terms of time spent by each species on a flower is presented in (Table 2). Among the honeybees, the mean foraging speed throughout the day period were found to be maximum for Apis florea (4. 31sec. ) followed by Apis cerana indica (3. $64 \mathrm{sec)}$ Apis mellifera (3. $05 \mathrm{sec}$ )and Apis dorsata (2.86 sec.)

Foraging rate of different honeybees in terms of number of flowers visited per minute per forager is presented in Table 3. Among the four honeybees Apis florea having the highest mean foraging rate (11. 1) which was followed by Apis cerana indica ( 10.91), Apis dorsata(10. 73) and Apis mellifera ( 10.11). It was observed that maximum numbers of flowers visited at 10. 00-12. $00 \mathrm{hrs}$ and 12. 00-14. $00 \mathrm{hrs}$. The bees spent more time in single flower, visited less number of flowers. During study, it was observed that Apis dorsata spent more time in single flower and visited less number of flowers. Butterflies visited during 08. 00 hrs to 12.00 noon. They fed on nectar 
and their stay on the flower varied from 20-25 sec. Moth visited 2-3 flowers per bout and stayed for 60$90 \mathrm{sec}$. and collect the pollen grains. Butterflies and Moth visited flowers very occasionally.

The visits of insect visitors were low at the time of commencement and cessation of flowering period but these remained high during mid flowering period. The differences may be due to variation in the floral density during the span of blooming of tree. Similar findings were reported by Kendell and Smith (1975);Wilson and Price (1977);Schaffer and Schaffer ( 1979);Schemske (1980);Dhaliwal and Atwal (1985) who stated that at the peak flowering, number of flowers was more and these were visited by larger number of pollinators. Another important factor for attraction of more visitors is found to be presence of aggregated/massed flowers is preferred by flower visitors. Faegri and Van der Pijl(1979) also support that aggregated massed flowers are preferred by flower visitors. Proctor et al (1996) reported that massing together of flowers in inflorescences enhances the floral display to attract pollinators.

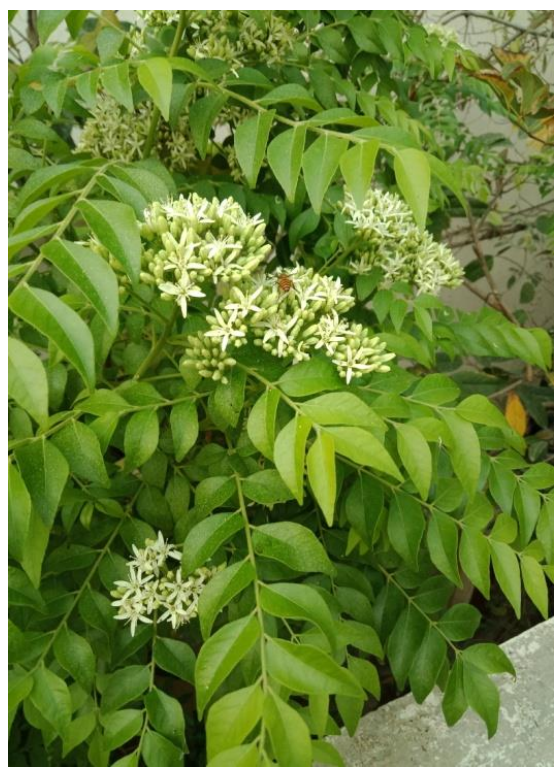

Apis florea

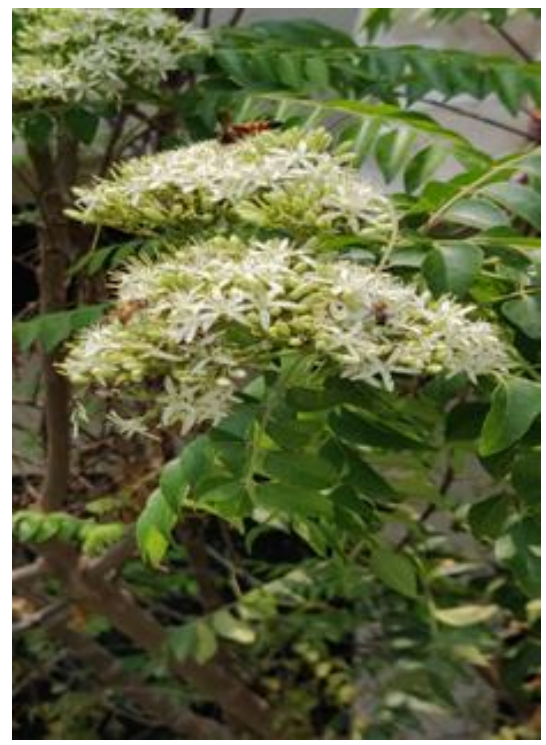

Apis florea, Apis dorsata, Apis cerana indica

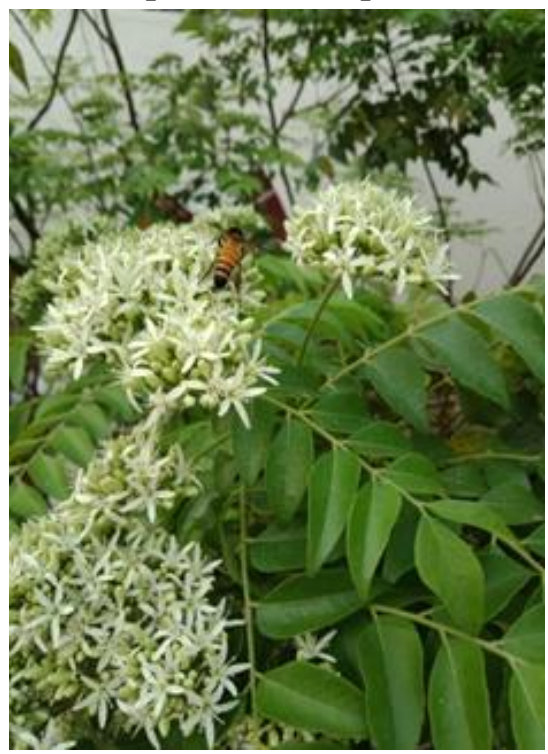

Apis dorsata

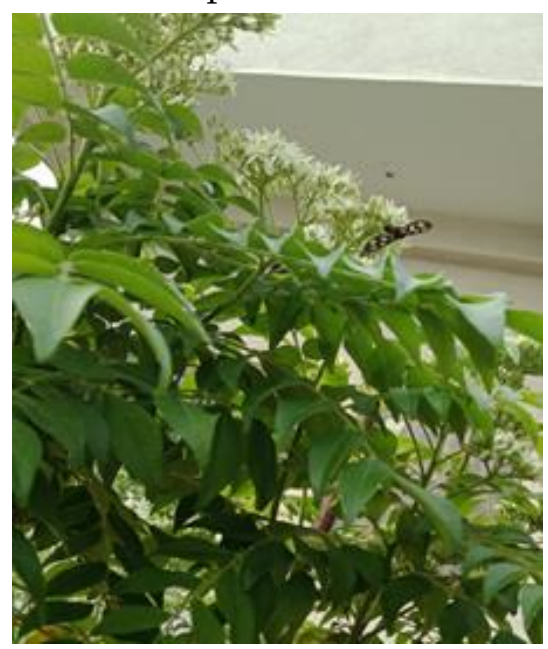

Moth 
Table 1. Diversity of different insect species on Murraya koenigii species

\begin{tabular}{|c|c|c|c|c|}
\hline Name of species & Order & Family & Foraging Type & $\begin{array}{c}\text { Visitors } \\
\text { Frequency }\end{array}$ \\
\hline Apis florea & Hymenoptera & Apideae & $\mathrm{P}, \mathrm{N}$ & $\mathrm{VF}$ \\
\hline Apis cerana indica & Hymenoptera & Apideae & $\mathrm{P}, \mathrm{N}$ & $\mathrm{VF}$ \\
\hline Apis dorsata & Hymenoptera & Apideae & $\mathrm{P}, \mathrm{N}$ & $\mathrm{VF}$ \\
\hline Apis mellifera & Hymenoptera & Apideae & $\mathrm{P}$, & $\mathrm{VF}$ \\
\hline Moth unidentified & Hymenoptera & unidentified & Pollen & VO \\
\hline Barbo cinnara & Lepidoptera & Hesperiidae & $\mathrm{N}$ & $\mathrm{VO}$ \\
\hline Catopsilla pyranthe & Lepidoptera & Pieridae & $\mathrm{N}$ & $\mathrm{VO}$ \\
\hline Hypolimnas bolina & Lepidoptera & Nymphalidae & $\mathrm{N}$ & $\mathrm{VO}$ \\
\hline Pachliopta aristolochiae & Lepidoptera & Papilionidae & $\mathrm{N}$ & $\mathrm{VO}$ \\
\hline Unidentified Butterfly & Lepidoptera & Unidentified & $\mathrm{N}$ & $\mathrm{VO}$ \\
\hline
\end{tabular}

Table 2 : Foraging speed of insect pollinators on Murraya koenigii flowers (time spent in second per flower per forager)

\begin{tabular}{|c|c|c|c|c|}
\hline Time & Apis florea & Apis cerana indica & Apis dorsata & Apis mellifera \\
\hline $600-800$ & 4.33 & 3.53 & 3.23 & 00 \\
\hline $800-1000$ & 4.46 & 4.13 & 3.53 & 3.73 \\
\hline $1000-1200$ & 5.20 & 4.60 & 3.40 & 3.53 \\
\hline $1200-1400$ & 5.06 & 4.46 & 2.53 & 2.86 \\
\hline $1400-1600$ & 3.73 & 2.73 & 2.33 & 2.60 \\
\hline $1600-1800$ & 3.13 & 2.40 & 00 & 00 \\
\hline Total & 25.91 & 21.85 & 17.18 & 18.31 \\
\hline Mean & 4.31 & 3.64 & 2.86 & 3.05 \\
\hline
\end{tabular}

Table 3 : Foraging rate of insect visitors on Murraya koenigii flowers (number of flowers visited per minute per forager)

\begin{tabular}{|c|c|c|c|c|}
\hline Time & Apis florea & Apis cerana indica & Apis dorsata & Apis mellifera \\
\hline $600-800$ & 10.43 & 9.62 & 9.45 & 8.56 \\
\hline $800-1000$ & 11.05 & 11.89 & 10.41 & 9.67 \\
\hline $1000-1200$ & 12.04 & 12.02 & 11.67 & 11.17 \\
\hline $1200-1400$ & 12.31 & 12.13 & 12.04 & 11.67 \\
\hline $1400-1600$ & 11.14 & 10.24 & 11.21 & 10.12 \\
\hline $1600-1800$ & 9.63 & 9.56 & 9.63 & 9.52 \\
\hline Total & 66.6 & 65.46 & 64.41 & 10.71 \\
\hline Mean & 11.1 & 10.91 & 10.73 & 11 \\
\hline
\end{tabular}

\section{REFERENCES}

[1]. Buchnan, L.S. and Nabhan, P.G. 1996. The forgotten pollinator: Island Press, Washington DC. USA, 292

[2]. Corbet, S.A.,Williams, I.H. and Osborne, J.L. 1991. Bees and the pollination of cropsand wild flowers in the European community. Bee World 72(2):47-59

[3]. Dhaliwal, J.S. and Atwal, A.S.1985.Effect of age of crop, plant spacing, soil moisture and phosphatic fertilizers on bee activity on Brassica crop. In pollination Biology : An 
Analysis.(ed.Kapil,R.P.) Inter India Publication .90-101.

[4]. Faegri and Van der, Pijl, L.1979.The principles of pollination ecology.3rd edn.Pergamon Press: Oxford

[5]. Free, J.B.1993.Insect pollination of crop plants.2nd edn.Academic Press ,London

[6]. Gahlawat, Dheeraj K., Jakhar,Savita and Dahiya ,Pushpa .2014.Journal of Phamacognosy and Phytochemistry 3(3);109-119

[7]. Kendell ,D.A. and Smith,B.D.1975.The foraging behavior of honeybee on ornamental Malus species used as pollinizers in apple orchards.Journal of Applied Ecology,12:465471.

[8]. Kluser,S. and Peduzzi,P.2007.Global pollinator decline:A Literature Review UNEP/GRID Europe UNEP

[9]. Proctor, M., Yeo, P.and Lack, A.1996.The natural history of pollination .Portland,OH:Timber Press.

[10]. Schaffer,W.M.and Schaffer,M.V.1979.The adaptive significance of variations in reproductive habit in the AGucate II:Pollinator foraging behaviour and selection for increased reproductive expenditure.Ecology,60:10511069.

[11]. Sihag, R.C. 1986. Insect pollination increased seed production in cruciferous and umbelliferous crops. J.Apic. Res. 25(2):121-126.

[12]. Wilson, M. and Price P.W.1977.The evolution of inflorescence size in Asclepias ( Asclepiadaceae).Tropical Agriculture, 54:353356.

\section{Cite this article as :}

M. M. Dhore, "Diversity and Foraging Behaviour of Insect Pollinators on Murraya koenigii (L. ) (Rutaceae)", International Journal of Scientific Research in Science and Technology (IJSRST), Online ISSN : 2395-602X, Print ISSN : 2395-6011, Volume 7 Issue 3, pp. 15-19, May-June 2020. Available at doi : https://doi.org/10.32628/IJSRST2072107 Journal URL : http://ijsrst.com/IJSRST2072107 